\title{
Incentives for asset growth: The different causes of monthly in-flows and out-flows of surviving managed futures funds
}

\author{
Paul Lajbcygier*, and Eric Shen \\ *Department of Econometrics \& Business Statistics, Department of Accounting \& Finance, \\ Monash University, Clayton, Victoria 3800, Australia. \\ Tel: + 613 99059694, Fax: + 613 9905159, \\ E-mail: Paul.Lajbcygier@BusEco.monash.edu.au \\ Received (in revised form): 27th November, 2006
}

Professor Paul Lajbcygier combines extensive industry and academic experience in investments. Since 1990, he has provided investment advice for various prominent domestic and international: funds managers, banks and hedge funds. He has published over 60 academic papers and generated over \$3.1 million in government grants and payments in-kind since 1995. He has sat on over ten journal editorial boards and conference programme committees and has also worked/researched at some of the best business schools in the world, including London Business School and the Stem School of Business, New York University.

Eric Shen completed his Masters under Paul Lajbcygier's supervision in 2006.

\section{Practical applications}

This work can benefit various communities within the alternative funds industry: academics, fund managers and fund allocators. From the perspective of academe, we have verified that assets growth and performance are linked. We have found a 'rational' model of monthly asset growth. Better forecasting of monthly asset growth is obtained by separating forecasts of asset in- and out-flows suggesting that different mechanisms drive them. A fund manager can use this study to isolate and focus upon those performance characteristics most important for monthly asset growth and hence, over time, increase the overall value of the fund. Finally, an asset allocator, CPO or fund of fund manager can use the model created in this study to identify managers which represent investment opportunities. If the manager has fewer assets under management than predicted, it may represent an allocation possibility. The allocator would also need to know what process and which markets were traded by the manager to gauge how fund returns would be adversely affected by increased assets under management.

\section{Abstract}

The typical hedge fund incentive contract stipulates

Journal of Derivatives \& Hedge Funds, Vol. 13 No. 4, 2008, pp. 287-303 (C) 2008 Palgrave Macmillan Ltd $1753-9641 \$ 30.00$ that 20 per cent of the profits are kept for the manager as an incentive to perform well: that is, provide large, persistent positive returns to investors. Rather than focusing on maximising their investor's wealth, managers may subvert this incentive scheme and focus on maximising assets under management instead. $B y$ doing so, managers may generate profits for themselves, even if their returns to their investors are small and do not persist. The aim of this work is to understand how a surviving manager may 
maximise monthly asset in-flow and minimise out-flow, and hence, maximise overall asset growth.

Surprisingly, we find that non-return-based performance characteristics like fund age, relative performance, and fund size are key factors when forecasting monthly asset flow. Furthermore, we find that different causes of in- and out-flows exist. Journal of Derivatives \& Hedge Funds (2008) 13, 287-303. doi:10.1057/palgrave.jdhf.1850085

Keywords: alternative investments; asset growth; performance characteristics; general additive models

\section{INTRODUCTION}

The aim of this work is to understand how an alternative funds manager may generate growth in assets under management by increasing monthly asset in-flows and reducing asset out-flows. Such a study is highly significant because growth in assets under management is vital for generating value to the fund management business.

To optimise its value, a hedge fund must accomplish three things: survive for as long as possible; produce the best performance possible; and grow assets under management as much as possible. While some research has been completed on the first two factors of value generation: survival and performance, virtually none has been completed on the causes of growth in assets under management.

Growth in assets under management is an important value generator for a hedge fund manager. Typically, a hedge fund will receive 20 per cent of the trading profits (above the highwater mark) as an incentive to perform well. The intent is to maximise investor wealth by providing strong incentives for managers to generate large, persistent 'absolute' (ie free from any traditional benchmark portfolio) returns. There is, however, little evidence that these incentive contracts work in the way intended: few, if any, managers generate large, persistent returns for their investors.

We believe that instead, hedge fund managers may subvert the performance contract and optimise value to the manager rather than the investor. It is possible for a fund with large assets under management to generate large dollar profits for the manager in the form of fees, even if its absolute returns to its investors are miniscule and do not persist!

Given the exponential growth of assets under management for the hedge fund sector over the last two decades (and given the lack of evidence indicating large, persistent returns for hedge funds (see section 'Data')), we argue that it has become easier for managers to maximise the value of their business by generating asset growth ${ }^{1}$ rather than generating large returns.

Understanding the causes of this growth in assets under management is important: is performance responsible in any way? If so, what is the nature of the performance which will foster asset growth?

Our aim is to answer these questions. We predict monthly asset flow as a function of select performance characteristics, and find that by creating two models, one to estimate in-flows and the other for out-flows, we greatly improve prediction accuracy. Since the two models use different performance characteristics (ie independent variables), this suggests that in- and out-flows have different causes.

\section{BACKGROUND TO MANAGED FUTURES}

In the last few years, alternative investments have grown in both number of managers and the 
amount of assets under management. Now, approximately $\$ 650$ billion $^{2}$ are managed in total.

Alternative fund managers operate under performance contracts that reward absolute performance above a high-water mark, independent from any benchmark ${ }^{3}$; relaxed regulations relative to mutual funds; and investment styles which have low return correlations to conventional mutual funds.

Hedge funds, private equity and real estate are all sub-classes of alternative investments. In this work we focus on a hedge fund style know as managed futures, (which are also known as commodity trading advisors (CTAs)). Such a manager operates a 'managed account' that trades a client's account on behalf of their clients, as opposed to a manager that operates a 'fund' that accepts a client's money into the fund.

Until recently, there has been exponential growth in total assets under management of managed futures. They have grown from $\$ 0.31$ billion to $\$ 130$ billion from 1980 to 2005 . $^{4}$

They can trade in over 150 equity, commodity, futures, options, and currency markets worldwide. Managed futures are highly diversified relative to traditional assets. The correlation between the S\&P 500 and managed futures indices is -0.25 . The conditional correlation to the S\&P 500 when it is falling is $-0.47 .{ }^{5}$ On the other hand, the correlation to the MSCI World Sovereign Bond Index is $0.36 .^{2}$

There are various styles of managed futures. We narrow our focus to the most prominent style: systematic diversified managed futures. Managers who belong to this style build trading systems by back-testing trading rules using historical data. Computer models are used to implement trading decisions. In theory, no discretion is permitted in the trading signal that is generated automatically by the computerised trading rules.

Trading often occurs on the most liquid global markets, which serves to minimise trading impact cost, and therefore maximises the assets under management. The philosophy is that the more the markets and time periods in which the models in the system trade, the less the model risk the fund takes.

\section{LITERATURE REVIEW}

As mentioned in the introduction, to maximise fund value, a manager must maximise: fund survival length, size and persistence of return performance and assets under management. We consider each of these literatures in turn.

First, Brown and Goetzmann ${ }^{6}$ and Getmansky and $\mathrm{Lo}^{7}$ consider fund survival. Brown and Goetzmann ${ }^{6}$ create a probit model of survival for managed futures. They find that survival depends upon fund age, excess volatility, relative performance, and absolute performance (ie on 'performance relative to high-water mark thresholds as well as to industry benchmarks').

Secondly, performance: a number of studies have considered hedge fund return performance in terms of magnitude and persistence. ${ }^{6,8,9}$ Given the emphasis on return performance in the incentive contract, we expect to find evidence of large, persistent returns. However, the literature (above) does not confirm this.

Intuitively, a fund should have return performance persistence over a long horizon to attract assets over the long term. Agarwal and Narayan ${ }^{9}$ find low but 'considerable' persistence using a quarterly horizon. Thus, it appears that return persistence ${ }^{10}$ only exists over the short term for hedge funds. 
Therefore (like mutual funds, see note 12), asset accumulation for hedge funds represents a paradox: intuitively, while long-run consistent return performance is required for long-run growth in assets under management, there is little evidence of it! This suggests that return performance alone cannot explain asset growth.

Nevertheless, a tacit assumption made by academics, investors and managers alike is that 'good' performance is rewarded by asset growth. If return performance does not encompass 'good' performance what other performance characteristics may? Perhaps, if we broaden our definition of 'good' performance to include non-return-based performance characteristics we may find a stronger link to asset growth. Also, due to the unique hedge fund performance contract, various dimensions of performance may be relevant, not just returns. What other performance measures should be included in measures of 'good' performance?

A few studies have considered non-traditional performance characteristics for return forecasting, including: relative performance, ${ }^{6}$ fund age ${ }^{11}$ and fund size. ${ }^{8}$ They find that each has some forecasting power, but none have related these characteristics to asset growth.

We consider this relationship now. Very few studies have focused on how performance is related to asset growth in the context of hedge funds. ${ }^{8,9,12-15}$ Goetzmann et al. ${ }^{3}$ consider the incentives for growth in assets under management in the context of hedge fund valuation. They argue that managers may be reluctant to grow and take on new money as this may negatively impact fund performance.

Owing to the quasi-arbitrage nature of trading in hedge funds and limited liquidity in the markets traded, there may be intrinsic limits to growth: The cost of growing too much may reduce return performance dramatically. They test a number of hypotheses including: that managers do not accept new money when they do well; and that larger funds do not continue to take new money. These hypotheses run counter to common sense and what has been observed in the mutual fund industry. However, they are validated: hedge funds do not act like mutual funds. They do not readily accept new money when they do well (ie obtain high returns) and larger funds do not take on new funds.

Conventional ideas of when and how assets flow which are true for the mutual fund industry (see note 12) are not true for the hedge fund industry. The 'bold new world' of alternative investments requires new concepts and models of the causes of asset growth.

These results help motivate our work. Our hypothesis is that hedge funds will grow assets as much as possible due to the tremendous financial incentives to do so. However, we understand that they will not want to grow assets to the extent where degradation in return performance will occur and consequently reduce (or eliminate) performances fees and ultimately destroy value in the fund management business.

How can a manager 'optimise' his assets under management such that return degradation is minimised? How does a managed futures manager maximise asset in-flow and minimise asset outflow? What 'causes' asset in- and out-flow? These are some of the key questions in this study.

Getmansky and $\mathrm{Lo}^{7}$ is the only study to explicitly model hedge fund asset flow. A piecewise linear regression model is created that has five explanatory variables: fund age, fund size, asset flow (in the previous time period), fund return, fund standard deviation (in the previous time period) and fund rank. The work is different from our own in numerous ways: 
there is no justification for the choice of explanatory variables; the relative ranking is ad hoc; only simple linear models are considered; quarterly not monthly returns data is used; and, the TASS database is used.

In summary, to maximise a funds value: survival, performance and funds under management must be maximised. While some studies have considered survival and performance, very little literature considers optimal growth in assets under management. A tacit assumption made by managers, asset allocators and academics alike is that 'good' performance will attract assets. However, it is not clear what constitutes good performance, or exactly how many assets will be attracted for such performance. Indeed, initial results show that performance characteristics that attract assets for mutual funds (ie high returns) will not do so for hedge funds. A funds capacity to profitably invest its assets is the limiting factor to asset growth. So, it is not clear why assets are attracted to hedge funds. Finding those variables that explain growth in assets for hedge funds and linking them to manager performance is the purpose of this study.

\section{DATA}

Our data for analysing asset flows in managed future funds were provided by Barclay Trading Group. Non-surviving funds are omitted from the database. 6,16

Although we have a 30-year history of monthly data, ${ }^{17}$ from 1st January, 1975 to 1st March, 2005, we calculated the growth in assets for the most recent common five-year window, from January 2000 to January 2005, ${ }^{18}$ including only those funds with monthly data for the entire five-year period. Each performance characteristic (Table 1) for each fund was calculated using the common five-year window. Creating a common five-year window controls for time-varying exogenous factors which may affect asset growth. ${ }^{19}$ It also means that each fund performance characteristic is estimated over the entire five-year window. Finally, since the majority of funds are new, they exist in this latest time period.

The dependent variable that we modelled in this work is monthly asset flow:

$$
A U M_{\mathrm{G}} R O W T H=A U M_{t}-A U M_{t-1}\left(r_{t}\right)
$$

and $r_{t}$ is the monthly return at time $t$. The product term above, adjusts assets under management, $A U M$, by the returns of the fund, $r_{t}$. This adjustment ensures that we consider only in-flows and out-flows (not growth in $A U M$ due to returns).

We focus our study on the most prevalent style, systematic diversified, because evidence indicates that style may affect growth (see Brown et al. ${ }^{6}$ ). Across all funds - 694 in this study for the entire history of the database, we found 55 self-reported styles. The most prevalent style was 'systematic-diversified' (208 funds, or 30 per cent of all funds).

In addition, we eliminated all first month records of asset flows since they represent initial assets under management rather than asset growth. In the end, 6,423 out of 6,893 records were kept (see appendix for details of outliers which were stripped).

Once this data is filtered we randomly divided the data into five equal data sets: ds1:ds5. This was used to validate the various models we shall fit to the data. Each data set was also divided into an in- and out-of-sample data set. The in-sample data is approximately 80 per cent of the data set, the out-of-sample the remaining 20 per cent. 


\section{Table 1: List of all characteristics tested in the study}

1 Monthly fund flow (monthly_fum_flow_dollars) [Dependant Variable]

2 Value of $\$ 1,000$ invested at inception (vami)

3 Length of life of fund (month_id)

4 Average monthly return of fund over its life (ror_mean)

5 Risk/standard deviation of a funds returns over its life (ror_sd)

6 Fund's average return divided by its risk (ror_mean_div_sd)

7 Maximum peak-to-trough drawdown on funds equity (maxdd)

8 Average monthly return divided by maximum drawdown (ror_mean_div_maxdd)

9 Average drawdown on funds equity (dd_mean)

10 Risk/standard deviation of draw-down (dd_sd)

11 Maximum time under water/number of months in a drawdown (maxtuw)

12 Average time under water/number of months in a drawdown (tuw_mean)

13 Risk/standard deviation of time under water (tuw_sd)
14 Correlation of fund returns with those of the S\&P 500 (sp500_correlation)

15 Average drawdown divided by drawdown risk (dd_mean_div_dd_sd)

16 Average time under water divided by time under water risk (tuw_mean_div_tuw_sd)

17 Skewness of funds returns (skewness)

18 Kurtosis of funds returns (kurtosis)

19 Percentage of a fund's monthly returns that are positive over life of fund (percentage_wins)

20 Average sequence length of positive returning months over life of fund (length_of_wins)

21 Maximum sequence length of positive returning months (max_wins_length)

22 Average sequence length of negative returning months over life of fund (length_of_losses)

23 Maximum sequence length of negative returning months (max_losses_length)

24 Return percentile of all funds based on total return (categorised_ror_rank)

25 Starting funds under management (start_window_fum)

The abbreviations (in brackets) are used throughout the paper.

The out-of-sample data set was used to obtain a more realistic estimate of the goodness of fit of the model which will be described in the results section.

\section{GENERALISED ADDITIVE MODELS}

Generalised additive models (GAMs) fit a smooth relationship between two or more variables through a scatter plot of data points.
We use a GAM to model the relationship between various performance characteristics and the monthly growth in assets under management (adjusted by returns).

GAMs are useful where the relationship between the variables is expected to be complex ${ }^{20,21}$ and not easily fitted by standard linear or nonlinear models; there is no a priori reason for using a particular model; and, where we would like the data to suggest the appropriate functional form. 
Given the nature of this study, in which we have no a priori expectations of either the functional form of the relation between performance characteristics and asset growth, GAMs are an appropriate tool for exploratory data analysis.

GAMs work by replacing the coefficients found in parametric models with a smoother which is a tool for summarising the trend of a response variable $(Y)$ as a function of one or more predictors $\left(X_{1} \ldots X_{p}\right)$. It produces a smooth estimate of the trend between $X$ and $Y$.

Smoothing takes place by 'local averaging'. In equation 1 , for each variable $X_{j}$, a unique, variable-specific smoothing function $f_{j}($.$) is$ applied.

$$
Y(\vec{X})=\alpha+\sum_{j=1}^{p} f_{j}\left(X_{j}\right)
$$

We use a locally weighted regression (Loess) smoother. For each point in a pre-chosen neighbourhood of $X_{i}$, the weights are proportional to the cubic distance of a point from $X_{i}$.

We also use a variable selection method to choose variables that are significant (and also choose their functional form using the same method). ${ }^{22}$ This choice is governed by minimising the Akaike information criterion (AIC). ${ }^{23,24}$

Our starting model contains all the independent variables we are considering, that is, the performance characteristics in Table $1 .{ }^{25,26} \mathrm{~A}$ series of models is fitted by moving each of the independent variables one step up or down in its regimen, relative to the formula of the current model. For the GAM model, this variable selection can produce a model that eliminates independent variables, converts them from nonlinear to linear, or leaves them as nonlinear.
Which one occurs depends on which one decreases AIC. ${ }^{27,28}$

If there are $p$ independent variables, at most $2 p-1$ models are considered. To avoid repetition, a record is kept of all the models ever visited (hence the -1 above). Once each of these models has been fitted, the best in terms of the AIC statistic is selected, and this defines the step. The entire process is repeated until either the maximum number of steps has been used, or until the AIC criterion cannot be decreased by any of the eligible steps. ${ }^{28}$

\section{PERFORMANCE CHARACTERISTICS}

In the previous section, we considered the statistical methodology chosen to estimate asset growth as a function of performance characteristics, but we have not yet considered which performance characteristics to include as independent variables in the GAM model.

From the literature review (see section 'Data'), we learned that very few studies have linked fund performance characteristics to growth although various studies have considered how variables such as persistence, relative performance ranking, risk, fund size, and age affect returns. So, there is no guidance available from the academic literature as to what performance characteristics are relevant to asset growth modelling.

So, we use the variables related to returns as a starting point. Various websites and trading analysis books are concerned with measuring the performance of alternative fund managers. The Institutional Advisory Service Group website ${ }^{29}$ is devoted to comparing alternative managers. It contains various performance measures, including return, standard deviation, percentage 
of profitable months, skewness, kurtosis, average gain and loss, and other ratios calculated from the data, such as Sterling, Calmar, and Sortino ratios. These performance characteristics are introduced with no justification; however, in this work, we verify that some of the performance characteristics in the non-academic literature are indeed useful predictors of growth.

We derive various statistics from the performance history of each of the funds in the systematic style, based purely on monthly returns. We use 25 performance characteristics, including: maximum drawdown; time under water (time between a fund's draw down and next high-water mark); and, mean return, as inputs for a GAM model that estimates asset growth (see Table 1).

\section{RESULTS}

In this work we aim to relate monthly asset flows to various performance characteristics, so that we may understand how a hedge fund may maximise asset in-flows and minimise asset out-flows.

We estimate various models of monthly asset flows as a function of the performance characteristics listed in Table 1. Using the variable selection methods discussed in section 'Performance characteristics', we find three models for predicting monthly asset flows. ${ }^{30}$

Our best model, 'all-flows', is:

$$
\begin{aligned}
& \text { monthly.fum.flow.dollars } \sim \text { monthly.aum.lag } \\
& \quad+\text { ror.mean.div.sd }+ \text { ror.mean }+ \text { rolling.mean.div.sd } \\
& \quad+\text { tuw.sd }+ \text { tuw.mean }+ \text { ror.sd }+ \text { sp500.correlation } \\
& \quad+\text { month.id }+ \text { max tuw }+ \text { categorised.ror.rank }
\end{aligned}
$$

However, if we model monthly cash in- and out-flows separately, we find that out of-sample results greatly improve.
The best in-flow model is:

$$
\begin{aligned}
& \text { monthly.fum.flow.dollars } \sim \text { monthly.aum.lag } \\
& + \text { maxtuw }+ \text { tuw.mean }+ \text { tuw.sd }+ \text { month.id } \\
& + \text { tuw.mean.div.tuw.sd }+ \text { categorised.ror.rank } \\
& + \text { rolling.mean.div.sd }
\end{aligned}
$$

While, the best out-flow model is: ${ }^{31}$

$$
\begin{gathered}
\text { abs }(\text { monthly.fum.flow.dollars }) \sim \operatorname{lo}(\text { monthly.aum.lag }) \\
\quad+\text { rolling.mean }+\mathrm{lo}(\text { ror.sd })+\mathrm{lo}(\text { vami })+\text { kurtosis } \\
\quad+\text { categorised.ror.rank }+ \text { rolling.mean.div.sd }
\end{gathered}
$$

Table 2 shows the out-of-sample results of all three models. The 'all-flows' model (Table 2, Panel A, LHS and equation 2) has a mean $R^{2}$ of 21.29 per cent across five out-of-sample data sets. On the other hand, our best model, which combines the 'in-flows' (equation 3) and the 'out-flows' (equation 4) models ${ }^{32}$ has a mean $R^{2}$ of 45 per cent across the same five outof-sample data sets (Table 2, Panel A, RHS). The reason for the success of the combined model is the separation of the in- and out-flow modelling.

The in-flows model (Table 2, Panel B and equation 3) has an average $R^{2}$ of 38.99 per cent (estimated on in-flows exclusively) and the out-flows model (Table 2, Panel B, equation 4) has an average $R^{2}$ of 36.5 per cent (estimated on out-flows exclusively): a considerable improvement compared to the all-flows model.

Note that the combined in- and out-flows model (Panel A, Table 2, RHS) does not outperform on all measures. The median absolute percentage error is lower for the all-flows model. This is probably because this model predicts the small flows more accurately than the combined model. 
Table 2: Out-of-sample results for in- and out-, all- and combination of in- and out-flows models

Panel $A$

\begin{tabular}{|c|c|c|c|c|c|c|}
\hline & \multicolumn{3}{|c|}{ All-flows } & \multicolumn{3}{|c|}{ In- and Out-flows } \\
\hline & $R^{2}(\%)$ & $\operatorname{Med} A E(\$)$ & MedAPE $(\%)$ & $R^{2}(\%)$ & $\operatorname{Med} A E(\$)$ & $\operatorname{Med} A P E(\%)$ \\
\hline Ds1 & 15.43 & 2811 & 231 & 44.6 & 2585 & 211 \\
\hline Ds2 & 16.63 & 2393 & 253 & 48.23 & 2502 & 277 \\
\hline Ds3 & 30.82 & 2554 & 253 & 47.1 & 2245 & 272 \\
\hline Ds4 & 19.9 & 2542 & 252 & 39.98 & 2547 & 299 \\
\hline Ds5 & 23.69 & 2554 & 254 & 45.1 & 2315 & 281 \\
\hline Mean & 21.29 & 2571 & 249 & 45 & 2439 & 268 \\
\hline
\end{tabular}

Panel B

\begin{tabular}{llllllll}
\hline & In-flows & \multicolumn{5}{c}{ Out-flows } \\
\cline { 2 - 3 } & $R^{2}(\%)$ & MedAE $(\$)$ & MedAPE $(\%)$ & & $R^{2}(\%)$ & MedAE $(\$)$ & MedAPE(\%) \\
\hline Ds1 & 37.14 & 3578 & 158 & 40.36 & 1459 & 334 \\
Ds2 & 41.24 & 3366 & 244 & 42.11 & 1404 & 312 \\
Ds3 & 42.47 & 3548 & 251 & 34.4 & 1397 & 312 \\
Ds4 & 33.72 & 3863 & 307 & 37.59 & 1306 & 295 \\
Ds5 & 40.39 & 3466 & 240 & 28.03 & 1321 & 344 \\
Mean & 38.99 & 3564 & 240 & 36.5 & 1377 & 319 \\
\hline
\end{tabular}

Figure 1 shows the out-of-sample performance of 62 different CTAs in the third out-of-sample data set (ie ds3). The actual flows are shown (shaded diamonds) as well as the allflows (hollow circles in Figure 1) and in- and out-flows combined (crosses in Figure 1). Each point along the $x$-axis represents a different fund and the corresponding point on the $y$-axis represents its asset flow for an (unknown) month.

From the figure we can see that the all-flows model, fit to this data, has difficulty in accurate predictions for large out-flows, over
$\$ 10$ million. From the prediction of the entire data sample we can see that the predicted outflows at months 3, 22, 26, 29 and 34 are all underestimated by this model. What's more, the in-flows at months 7, 18, 28, 33, 36, 39 and 59 are all underestimated too. It appears that the model is confounded by the requirement to simultaneously predict both in-flows and out-flows accurately.

The problem is rectified by splitting the data into cash in-flows and out-flows, estimating separate models on each and then using them to make predictions. We obtain greater accuracy for 




Figure 1: Prediction of data sample 3 for the various models. The coloured diamonds represent actual flows while the hollow circles are predictions for the all-flows model (equation 1), $R^{2}=10$ per cent, and the crosses are predictions for the combined in- and out-flows, $R^{2}=42$ per cent (equations 2 and 3 )

the in-flows model: those at months $7,18,33$, 36 and 59 are now accurately predicted.

However, the large in-flows at 9 and 28 are still inaccurate. The out-flows model greatly improves prediction for out-flows 3 and 34, and marginally improves the other aforementioned problematical out-flows associated with the allflows model.

So, we can see from Figures 1 and 2, Table 2 and equations $2-4$, that by creating two models: one for in-flows and the other for out-flows, we obtain much more accurate predictions of monthly asset flow.

It is noteworthy that the majority of performance characteristics responsible for asset in- and out-flow (in equations 3 and 4) are different, which suggests different 'causes' for cash in- and out-flows. We will consider the evidence for the separate causes of asset in- and out-flows next.
Table 3 lists all the performance characteristics (ie independent variables) included in all three models (equations 2-4). For each, the number at the top represents the $x$-intercept (the point at which flows change from positive to negative). A ' $+/-$ ' means that the gradient is positive/ negative for the performance characteristic under consideration. An NA means that the variable is not included in the model. A ' $*$ ' means that the variable is nonlinear. The numbers in brackets represent the range that the independent variable acts on the dependent variable (ie monthly asset flow) and is a measure of the influence of the independent variable on the dependent.

If we consider each performance characteristic (which are all linear) for in-flows (equation 3), from Table 3, we find that a fund that attracts large monthly dollar assets under management should: have large lagged assets under 

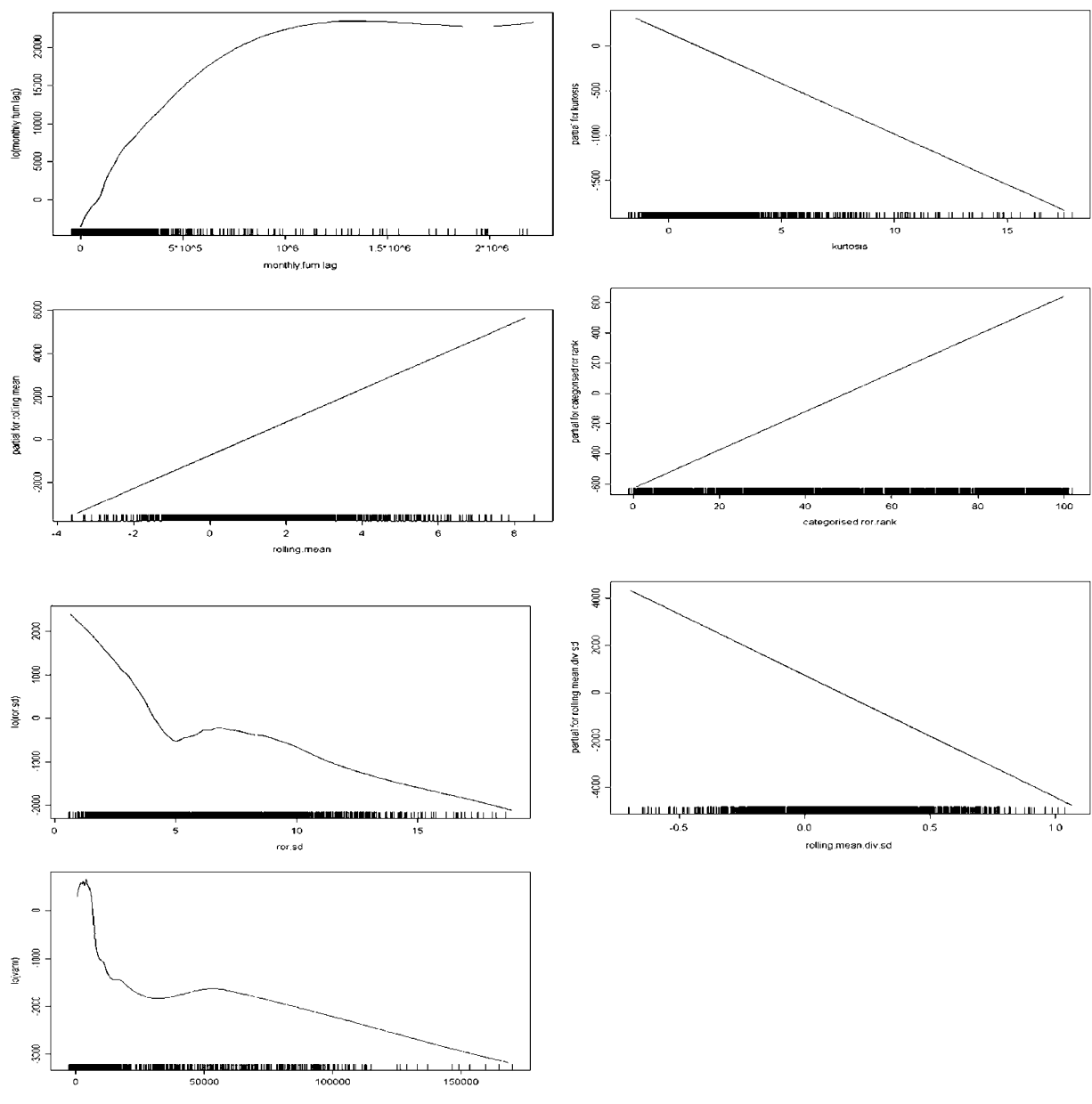

Figure 2: The graphs for the out-flows model

management (monthly.aum.lag); a large maximum time under water (max.tuw); a small average time under water (tuw.mean); small time under water variability (tuw.sd); be young (small month.id); be ranked as highly as possible (large categorised.ror.rank); and, have as large a 12 monthly risk-adjusted return as possible (rolling.mean.div.sd).

Now, let us consider the out-flows model (equation 4). This model is different from the in-flow model in two main ways: it has three nonlinear terms; and it includes variables omitted by the in-flows model.

Figure 2 shows each of the independent variables which contribute to the overall forecast of monthly out-flow. For a given fund, if we know each of the (seven) independent variable values, we can find the total forecast out-flow by simply adding together each contribution that each variable makes (this is why GAMs are known as additive and why they are useful in exploratory data analysis since they can be easily interpreted, see equation 1).

We can also see from Figure 2 that monthly out-flows ${ }^{33}$ are a function of seven variables, 
Table 3: Each variable chosen for each model using the variable selection procedures discussed above

\begin{tabular}{|c|c|c|c|}
\hline Variables & All-flow & In-flow & Out-flow \\
\hline month.id & $\begin{array}{l}100.0 \\
- \\
(-3000,1000)\end{array}$ & $\begin{array}{l}100 \\
- \\
(-6000,2000)\end{array}$ & NA \\
\hline rolling.mean.div.sd & $\begin{array}{l}0.2 \\
+ \\
(-6000,6000)\end{array}$ & $\begin{array}{l}0.2 \\
+ \\
(-400,400)\end{array}$ & $\begin{array}{l}0.2 \\
- \\
(-400,400)\end{array}$ \\
\hline monthly.aum.lag & $\begin{array}{l}0.0 \\
+ \\
(0,50000)\end{array}$ & $\begin{array}{l}0.0 \\
+ \\
(0,100000)\end{array}$ & $\begin{array}{l}0.0 \\
+\star \\
(0,20000)\end{array}$ \\
\hline categorised.ror.rank & $\begin{array}{l}50.0 \\
+ \\
(-200,200)\end{array}$ & $\begin{array}{l}50.0 \\
+ \\
(-500,500)\end{array}$ & $\begin{array}{l}50.0 \\
+ \\
(-600,600)\end{array}$ \\
\hline ror.mean.div.sd & $\begin{array}{l}0.2 \\
+ \\
(-15000,10000)\end{array}$ & NA & NA \\
\hline Maxtuw & $\begin{array}{l}7.5 \\
+ \\
(-400,800)\end{array}$ & $\begin{array}{l}7.5 \\
+ \\
(-5000,20000)\end{array}$ & NA \\
\hline tuw.mean & $\begin{array}{l}5.0 \\
- \\
(-4000,2000)\end{array}$ & $\begin{array}{l}5.0 \\
- \\
(-10000,5000)\end{array}$ & NA \\
\hline ror.mean & $\begin{array}{l}1.0 \\
- \\
(-10000,10000)\end{array}$ & NA & NA \\
\hline ror.sd & $\begin{array}{l}6.0 \\
+ \\
(-1000,4000)\end{array}$ & NA & $\begin{array}{l}4.0 \\
-\star \\
(-2000,2000)\end{array}$ \\
\hline sp500.correlation & $\begin{array}{l}-0.25 \\
- \\
(-3000,1000)\end{array}$ & NA & NA \\
\hline tuw.mean.div.tuw.sd & NA & $\begin{array}{l}2.0 \\
+ \\
(-1000,4000)\end{array}$ & NA \\
\hline tuw.sd & $\begin{array}{l}- \\
(-6000,2000)\end{array}$ & $\begin{array}{l}- \\
(-15000,5000)\end{array}$ & NA \\
\hline
\end{tabular}


Table 3: Continued

\begin{tabular}{llll}
\hline Variables & All-flow & In-flow & Out-flow \\
\hline Kurtosis & NA & NA & 1.0 \\
& & & $(-1500,500)$ \\
rolling.mean & NA & NA & 1.0 \\
& & & + \\
Vami & NA & NA & $(-2000,6000)$ \\
& & & $-\star$
\end{tabular}

The dependent variable is the monthly asset flow, the independent variable is that listed in the table. The number at the top is the $x$-intercept. A+/- means that the gradient is positive/negative. An NA means that the variable is not included in the model. A * means that the variable is nonlinear. The numbers in brackets represent the range of the independent variable and is thus a measure of the influence of the independent variable on the dependent.

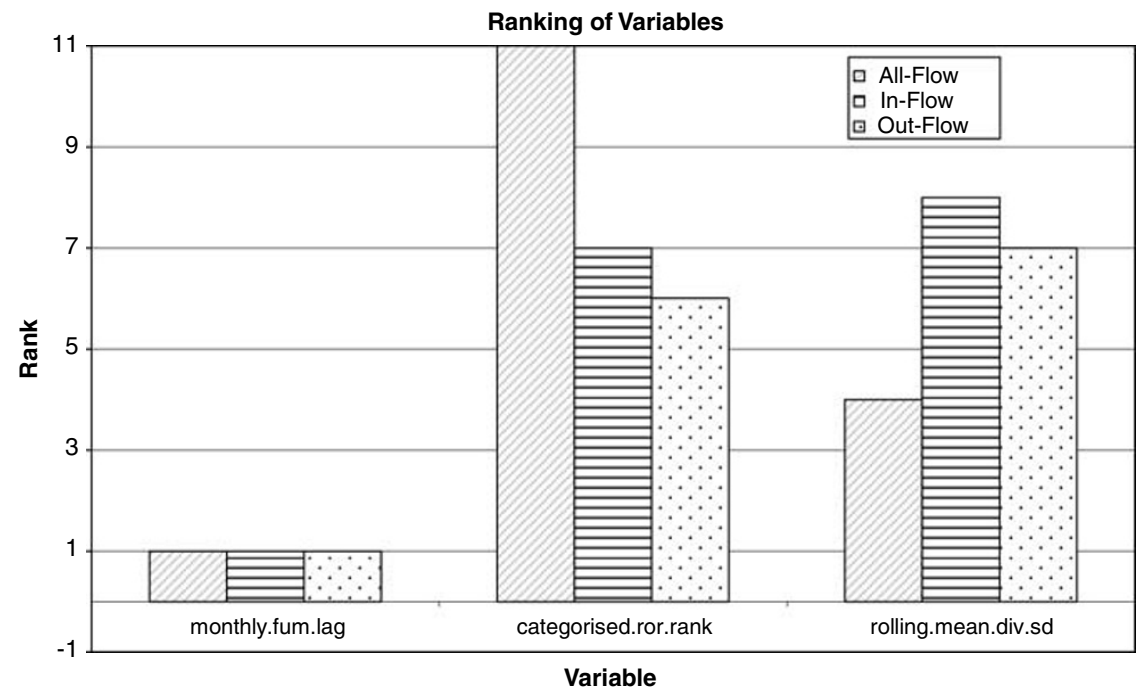

Figure 3: Rankings of each of the variables in common among the all-(diagonal stripes), in-(horizontal stripes), and out-flow (dots) models

three of which are nonlinear: monthly.aum. lag; ror.sd; and vami. We will consider these next.
Firstly, monthly out-flow is a nonlinear function of lagged monthly assets under management (monthly.aum.lag) and it follows a 
logarithm function. The rate of growth of outflows slows as the assets under management increase. In contrast, the monthly in-flow grows constantly as a function of lagged monthly assets (see Table 3).

Secondly, monthly out-flow is a nonlinear function of return risk (ror.sd): following an ' $\mathrm{L}$ ' shape, those funds which do not show enough risk are penalised in terms of attracting assets under management. Funds that have a risk of greater than 4 per cent per month have a small in-flow regardless of how much additional risk they take on. An out-flow of between 5 and 10 per cent means that the asset flow is constant. Greater than 10 per cent means far greater inflows occur. This makes sense, an investor does not wish to tie-up assets with a manager which does not trade with enough risk, ${ }^{34}$ since they cannot generate large returns.

Finally, from Figure 2 (bottom, left hand side) we can see that monthly out-flow is a nonlinear function of VAMI. The value added monthly index (ie VAMI) tells us how much money we would have, having invested $\$ 1,000$. The aim is to provide a measure of cumulative returns. The response between VAMI and assets is ' $\mathrm{L}$ ' shaped. There is a sharp increase in in-flows for VAMI between $\$ 10,000$ and $\$ 25,000$.

Then a more gradual increase after $\$ 25,000$. This result suggests that funds that have returned 25 times or more, have near maximal effect on asset in-flow.

The remaining out-flow variables are all linear. To minimise out-flow a manager must ensure that: rolling average 12 monthly returns are less than 1 per cent; the fund's returns have high kurtosis; relative ranking ${ }^{35}$ is low; and, riskadjusted returns are high.

Three performance characteristics are common among all models (equations 2-4): lagged size of assets under management (monthly.aum.lag), cumulative ranked return performance (categorised.ror.rank) and yearly rolling risk-adjusted returns (rolling.mean.div.sd).

Figure 3 compares the influence of these performance characteristics. ${ }^{36}$ Monthly.aum.lag is essential for accurate forecasts of asset flow dollar forecasts: it is ranked most influential (ie first) for each model (equations 2-4). Categorised.ror.rank is the least important for the all-flows model (11th of 11 performance characteristics in the model) and second least important for the in- (7th of 8 variables) and out-flows models (6th of 7 variables).

Rolling.mean.div.sd is least important for inand out-flow models but moderately important for the all-flows model (4th of 11 variables). Risk-adjusted returns are not influential in forecasts of asset flow.

Apart from the performance characteristics discussed above, there are no additional performance characteristics in common between the in- and out-flows models (equations 3 and 4). This suggests that the causes of in- and outflow are quite different. In particular, time under water, which is ubiquitous in the in-flow model, is not important for out-flows.

\section{CONCLUSION}

The typical hedge fund incentive contract stipulates that 20 per cent of the profits are kept for the manager as an incentive to perform well: that is, provide large, persistent positive returns. This incentive fee is both an incentive for generating positive absolute returns and also for growing assets under management since both generate profit for the manager. 
However, hedge fund managers may exploit these incentives and subvert their original intent. Rather than focusing on maximising their investor's wealth, managers may instead focus on maximising the value of their fund management business by growing assets under management.

The aim of this work has been to understand how a manager can minimise out-flows and maximise in-flows: that is, maximise asset growth. We have found that non-return-based performance characteristics like fund age, relative performance, absolute risk-adjust performance, and fund size are key factors when considering monthly asset flow and hence overall asset growth.

We also found that if we divide the modelling into two: focusing on in-flows and out-flows separately, out-of-sample forecast accuracy improves, so that we may explain almost 50 per cent of the variance of monthly asset flows.

Furthermore, when we examine the separate in- and out-flow models the majority of variables are not in common. This suggests that different causes of in- and out-flows exist.

What of the remaining 50 per cent of the variance of monthly asset flows left unexplained? There may be many causes of this, not considered in this study: reputation; flows into the sector; advertising; and perhaps, noise too may account for this remaining portion of unexplained variance. This is left for further work.

\section{References and Notes}

1 Of course, managers must take care in order not to adversely affect their returns by increasing assets under management too much, due to the greater adverse market impact their trading will have. After all, a fund that has no positive returns will not earn any management fees.

2 Black, K. (2004) 'Managing A Hedge Fund', McGrawHill, New York.

3 Goetzmann, W., Ingersoll, J. and Ross, S. (2003)

'High-Water Marks and Hedge Fund Management
Contracts', The Journal of Finance, Vol. LVIII, No. 4, pp. 1685-1717.

4 Barclay Trading Group (2005): http:// www.barclaygrp.com/.

5 It has been argued that this negative correlation provides great diversification benefit to an investor irrespective of a manager's returns. We do not agree. This statistic is calculated for all falling months. It may be incorrect for extreme negative months. When markets crash, liquidity 'dries up' and markets become highly correlated just when diversification is most needed.

6 Brown, S. and Goetzmann, W. (2001) 'Careers and Survival: Competition in the Hedge Fund and CTA Industry', The Journal of Finance, Vol. LVI, No. 5, pp. $1868-1885$.

7 Getmansky, M. and Lo, A. (2004) 'Sifting Through the Wreckage: Lessons from Recent Hedge-Fund Liquidations', MIT, Sloan School of Management, Vol. 40.

8 Harri, A. and Brorsen, B. (2004) 'Performance Persistence and the Source of Returns for Hedge Funds', Applied Financial Economics, Vol. 14, pp. 131-141.

9 Agarwal, V. and Narayan, Y. (2000) 'Multi Period Performance Persistence Analysis of Hedge Funds', Journal of Financial and Quantitative Analysis, Vol. 35, No. 3, pp. 327-342.

10 Return persistence refers to how similar a funds returns are from one period to the next.

11 Liang, B. (2000) 'Hedge Funds: The Living and the Dead', Journal of Financial and Quantitative Analysis, Vol. 35, No. 3, pp. 309-326.

12 There has been some literature on asset flow and its effect on returns for mutual funds. New studies of asset flow that focus on alternative investments, such as managed futures, are necessary for three reasons: unlike mutual fund managers ${ }^{13-15}$ alternative mangers do not readily accept new assets when they perform well; the alternative investment industry has been thought to be return-focused, due to the incentive fees in the performance contract, but there is little evidence of long-term absolute return persistence for alternative manages, and therefore return persistence cannot explain long-term asset growth, ${ }^{8,9}$ as it may with mutual funds, ${ }^{14,15}$ finally, studies of asset flow in mutual funds have focused on traditional performance characteristics such as return and risk, ${ }^{14}$ non-standard performance characteristics, such as relative performance, fund age, and time under water, neglected in most mutual fund studies of asset flow, may be of use in predicting assets growth for alternative managers because of their peculiar incentive contracts.

13 Berk, J. and Green, R. (2004) 'Mutual Fund Flows and Performance In Rational Markets', Journal Of Political Economy, Vol. 112, pp. 1269-1295. 
14 Chevallier, J. and Ellison, G. (1997) 'Risk Taking by Mutual Funds as a Response to Incentives', Journal of Political Economy, Vol. 105, No. 6, pp. 1167-1200.

15 Sirri, E. and Tufano, P. (1998) 'Costly Search and Mutual Fund Flows', The Journal of Finance, Vol. LIII, No. 5, pp. 1589-1622.

16 While this introduces survivorship bias (see Brown et al. ${ }^{6}$ ) this is not problematic for our study, as we are interested in modelling the growth of funds under management of successful managers (ie those mangers who survive).

17 Few funds have a monthly history for each of the 30 years.

18 This window contains 54 per cent of all systematic diversified funds in the database.

19 Over different time periods, different exogenous industry/economic factors affect the entire alternative investment sector, fund styles, and individual funds differently. We would not expect that the economy and industry factors affecting fund growth in 1975 to be the same as those in 2005. In 1975, one style of hedge funds may have been attractive to investors, while in 2005 , another may have been attractive.

20 Bassett, A. and Bishop, G. (2005) 'GAM Models', http://www.bioss.ac.uk/smart/unix/mgam/slides/ frames.htm.

21 Hastie, T. and Tibshirani, R. (1990) 'Generalized Additive Models', Chapman \& Hall, London.

22 The variable selection procedure was used to construct a set of plausible models, rather than used to find the definitively best model. Numerous competitor models were compared.

23 The AIC is a log-likelihood-based procedure that penalises larger models with equal fit. Although widely used it can have serious shortcomings: including a bias when the sample size is small. ${ }^{24}$

24 Hurvich, C.M. and Tsai, C.L. (1995) 'Model Selection for Extended Quasi-Liklihood Models in Small Samples', Biometrics, Vol. 51, pp. 1077-1084.

25 Many of the variables in Table 1 will be correlated. This introduces the problem of 'concurvity' (the nonlinear analog to multicolinearity). Concurvity leads to variance inflation of the fitted parameters in a GAM. A consequence of undetected and unadjusted concurvity can be inflated type I error. ${ }^{26}$ Thus, instead of using our variable selection method to isolate the (perhaps incorrect) 'best' model we compare a number of competitor models on our out-of-sample data. Contact the authors for more details.

26 Ramsay, T., Burnett, R. and Krewski, D. (2003) 'Exploring Bias in a Generalized Additive Model for
Spatial Air Pollution Data', Environmental Health Perspectives, Vol. 111, No. 10, pp. 1283-1288.

27 A modified AIC is used with additional terms for the smoother, its degrees of freedom is one based on the principles of quasi-likelihood.

28 MathSoft (1994) 'S-plus for Windows Version 3.2 Supplement', Seattle: StarSci, a division of Mathsoft Inc.

29 Jonkeer, P. (2000) Institutional Advisory Services Group, http://www.iasg.com/.

30 Each of the data sets: ds1-ds5, were split into an in-sample data set comprising 80 per cent of the data and an out-sample data set, comprising of the remaining 20 per cent of data. For each in-sample data set a model was estimated using the variable selection techniques of section 'Performance characteristics'. Only those variables included in each of the in-sample data sets were chosen for the final model. If a variable was deemed to be nonlinear in three or more data sets, it was forced to be nonlinear.

31 Note that $\operatorname{abs}($.$) is the absolute value of the dependent$ variable and $\mathrm{lo}($.$) indicates that a non-parametric loess$ curve is fit to the independent variable.

32 An important caveat is that we assume perfect foresight as to the sign of the next flow. Of course, in reality, we do not have this perfect foresight, however, the point is that by separating our analysis into in- and out-flows we have the capacity, in theory, to greatly improve prediction accuracy. What's more, this increased ability suggests different mechanisms for inand out-flows.

33 We should note that the dependent value in the outflow equation (equation 4) is the absolute value of monthly asset flow, and not simply the monthly asset flow. This means that, in Figure 2, any value above zero represents an out-flow, while values below zero represent in-flows. For example, if we consider the 'rolling.mean.div.sd' graph (Figure 2, bottom graph, right hand side), we can see that negative rolling means result in out-flows and positive rolling means result in in-flows.

34 In the typical CTA contract, a manager will earn a small management fee (eg 1 per cent) regardless of performance.

35 This result is unexpected: we would have thought that high ranking would cause small out-flow.

36 The figure ranks each variable in order of influence on the dependent variable. This 'influence' is obtained from the range of each variable (Figure 2) and listed for each variable and model in Table 3. 


\section{APPENDIX}

\section{Conditions and number of outliers excluded}

See Table A1.

1. monthly.fum.flow.dollars $<271,000$ : 1 record is eliminated due to far out of range.

2. $-0.8<$ monthly.fum.flow $<1.1$ : 29 records are eliminated because empirically we found that GAM models are unable to predict well on occasions of a large flow with a small asset base or a small asset flow with a large asset base. This ratio is not incorporated in

Table A1: Rules of eliminating outliers from input variables

$\begin{array}{ll}\begin{array}{ll}\text { monthly.fum.flow.dollars } \\ <271,000\end{array} & \text { length.of.wins }>0 \\ \text { monthly.fum.flow }<1.1 & \text { length.of.wins }<6 \\ \text { monthly.fum.flow }>-0.8 & \text { length.of.losses }<5.5 \\ \text { dd.mean.div.dd.sd }<20 & \text { ror.mean.div.maxdd } \\ & <2.5 \\ \text { ror.mean.div.sd }<1.3 & \text { ror.mean.div.maxdd } \\ \text { ror.mean.div.sd }>-1.5 & >-0.5 \\ & \text { rolling.mean.div.sd } \\ \text { ror.mean }>-6 & <1.2 \\ \text { ror.mean }<6.5 & \text { rolling.mean.div.sd } \\ \text { ror.sd }<20 & >-0.7 \\ \text { dd.mean }<45 & \text { delta.ror.mean }<4 \\ \text { dd.sd }<18 & \text { delta.ror.mean }>-4 \\ \text { maxtuw }<30 & \text { rolling.mean }<9 \\ \text { tuw.mean }<17 & \text { rolling.mean }>-3.5 \\ & \text { rolling.sd }<22 \\ & \text { monthly.aum.lag } \\ & <2,300,000\end{array}$

variables constructing GAM models but used as a rule of getting rid of outliers here to assist adjusting the more accurate prediction ability of GAMs.

3. dd.mean.div.dd.sd $<20$ : 45 records are eliminated. Owing to the division nature of this variable, these records include the extraordinary data points of over 60 on this variable compared with less than 20 of dd.mean.div.dd.sd of the rest. Including there records are also likely to cause the failure of generating GAM models.

4. $-1.5<$ ror.mean.div.sd $<1.3: 15$ records excluded due to that the out of range of such records distorts GAMs' prediction.

5. $-6<$ ror.mean $<6.5$ : 27 records excluded for the sake of restriction on data range.

6. ror.sd $<20$ : 8 records excluded as out-ofrange data points.

7. dd.mean $<45: 8$ records excluded.

8. dd.sd <18: 102 records excluded to strictly restrict the data range.

9. maxtuw $<30$ : 60 records excluded to confine the data range.

10. tuw.mean $<17$ : 3 records are eliminated.

11. $0<$ length.of.wins $<6: 11$ records excluded. The reason we eliminate records with 0 and 6 value of length.of.wins is that such records might affect the prediction of GAMs because most records have data points between 1 and 5 for this variable.

12. length.of.losses $<5.5$ : 5 records excluded.

13. $-0.5<$ ror.mean.div.maxdd $<2.5$ : 23 records excluded.

14. $-0.7<$ rolling.mean.div.sd $<1.2$ : 11 records excluded.

15. $-4<$ delta.ror.mean $<4: 14$ records excluded. 